\title{
Rational use of the fixed combination of dorzolamide - timolol in the management of raised intraocular pressure and glaucoma
}

\author{
Jason Yeh' \\ Daniel Kravitz ${ }^{2}$ \\ Brian Francis' \\ 'Doheny Eye Institute, Keck School \\ of Medicine, University of Southern \\ California, Los Angeles, CA, USA; \\ ${ }^{2}$ Tulane University, School of Medicine, \\ New Orleans, LA, USA
}

\begin{abstract}
Glaucoma is a multifactorial optic neuropathy in which the main therapeutic target is lowering of intraocular pressure (IOP) in order to retard the progression of existing structural and functional damage. The three mainstays of treatment are pharmacologic, laser, and surgical. The primary standard therapy in patients with open-angle glaucoma or ocular hypertension is topical medication. When monotherapy does not adequately lower the intraocular pressure, one or more agents are added or substituted. Combination pharmacotherapy such as Cosopt ${ }^{\mathbb{B}}$ is available to improve efficacy and simplify medication regimen. A fixed combination of two ocular hypotensive drugs (the carbonic anhydrase inhibitor dorzolamide and the beta-adrenoceptor antagonist timolol), Cosopt $^{\circledR}$ is indicated for the treatment of elevated IOP in patients with open-angle glaucoma or ocular hypertension insufficiently responsive to topical beta-adrenoceptor antagonist monotherapy. Compared with concomitant therapy with the individual components, the primary advantage of fixed combination dorzolamide - timolol is convenience, which may also improve compliance. Clinical trials have demonstrated that the fixed combination dorzolamide - timolol is safe, effective and generally well tolerated in lowering IOP in patients with open angle glaucoma or ocular hypertension, including individuals uncontrolled on beta-adrenoceptor antagonist or other monotherapy.
\end{abstract}

Keywords: glaucoma, ocular hypertension, Cosopt ${ }^{\mathbb{R}}$, fixed combination dorzolamide - timolol, dorzolamide, timolol

\section{Introduction}

Glaucoma is a multifactorial optic neuropathy with elevated intraocular pressure (IOP) as a major risk factor. Increased IOP can eventually lead to characteristic glaucomatous optic nerve damage and corresponding visual field defects. This is one of the most common causes of blindness in the entire world, thus it is necessary that proper interventions be implemented at the earliest possible time to prevent further visual impairment (Martinez et al 1982). Lowering the IOP has been shown to significantly reduce the risk of progression of glaucoma damage. Furthermore, the higher or lower the IOP at follow-up produced a respective increase or decrease in risk of progression (Leskea et al 2004). This holds true for both patients with ocular hypertension and those with normal tension glaucoma. Patients with ocular hypertension are those with IOP greater than $21 \mathrm{mmHg}$ but do not exhibit optic nerve features suggestive of early glaucoma or do not have suspicious visual field defects (Gordon et al 2002). The Normal Tension Glaucoma Study Group showed that a lowering of the IOP by $30 \%$, regardless of method, had less progression of visual field loss compared to those without treatments. This reduced IOP can be obtained and maintained by topical ophthalmic medications and/or laser trabeculoplasty (Schulzer et al 1992). Thus, the reduction of IOP to a level compatible with preservation of optic nerve function and stability 
of visual fields remains the primary goal of all therapeutic modalities used in the treatment of glaucoma.

There are three mainstays to treatment of glaucoma: pharmacologic, laser, or surgical treatments. The first line of therapy is topical medication. Many medications now exist to help control IOP in a variety of classes. Beta-adrenergic antagonists have been a mainstay of therapy for many years. They remain the most commonly prescribed drug, but more recent classes of glaucoma medications have come into favor. These include prostaglandin F2-alpha agonists, alpha-2 agonists, and carbonic anhydrase inhibitors. The prostaglandin analogues have gained favor as primary therapy, but in many instances, beta-blockers remain the first-line therapy in treatment of glaucoma (Bateman et al 2002). Sometimes single agents do not achieve the desired therapeutic effects, thus combinations of medications from various classes can be used to attempt to achieve the desired results. When more medications are added, however, the treatment regimen becomes more complicated and patient compliance becomes a concern (Kaiserman et al 2005). It is for this reason that combination pharmacotherapy has come into favor in glaucoma treatment (Martone and Mead 2001).

If pharmacotherapy continues to provide insufficient lowering of IOP, surgical options exist. Glaucoma surgery can be accomplished with laser or incisional surgical techniques (Bateman 2002). The 5-year results of the Collaborative Initial Glaucoma Treatment Study (CIGTS) showed that both initial surgical or medical therapy resulted in similar visual field outcome. While there was a noted decreased visual acuity initially in the surgery treated group, this difference seemed to resolve as the length of follow-up progressed (Lichter et al 2001). Thus, patients with glaucoma are treated either medically or surgically to lower the intraocular pressure in order to prevent further progression of the glaucoma disease process.

\section{Pharmacology, mode of action, pharmacokinetics}

One combination topical medication commercially available is Cosopt ${ }^{\mathbb{B}}$ (Merck and Co., Inc., Whitehouse Station, NJ, USA), which consists of dorzolamide hydrochloride $2 \%$ (CAS Registry \# 130693) and timolol maleate 0.5\% (CAS Registry \# 26921-17-5). Each mL of Cosopt ${ }^{\circledR}$ contains $20 \mathrm{mg}$ dorzolamide (22.26 mg dorzolamide hydrochloride) and $5 \mathrm{mg}$ timolol (6.83 mg timolol maleate), as well as sodium citrate, hydroxyethyl cellulose, sodium hydroxide, mannitol, water, and $0.0075 \%$ benzalkonium chloride as a preservative (Cosopt $t^{\circledR}$ online 2007). The formulation is available in
5 or $10 \mathrm{~mL}$ quantities containing 175 and 321 drops/bottle, respectively. Dorzolamide hydrochloride is a topical carbonic anhydrase II inhibitor and timolol maleate is a topical betaadrenergic receptor blocking agent. In combination, they are approved to reduce elevated IOP in patients with open-angle glaucoma or ocular hypertension and with insufficient IOP response to beta-blockers monotherapy $\left(\mathrm{Cosopt}^{\circledR}\right.$ online 2007).

Both dorzolamide and timolol help reduce IOP by decreasing the production of aqueous humor by the ciliary body. Carbonic anhydrase inhibition slows the formation of bicarbonate ions thereby decreasing the amount of sodium and fluid transport. With such a decrease in fluid transport comes a decreased production of aqueous humor. Dorzolamide decreases the secretion of aqueous humor in the ciliary processes by inhibition of carbonic anhydrase II, the most active isoenzyme and found primarily in red blood cells. Thus, chronic administration of dorzolamide causes an accumulation of the medication within red blood cells. This drug also binds moderately to plasma proteins. Metabolism of dorzolamide produces $\mathrm{N}$-desthyl which also binds to red blood cells to inhibit carbonic anhydrase I to a greater extent than carbonic anhydrase II. The major route of excretion is through the urine for both the parent and metabolite drug. Upon discontinuation of the medication there is a rapid initial decline of the medicine from the red blood cells followed by a much slower decline due to an elimination-phase half-life of approximately 4 months. Carbonic anhydrase inhibitor has been reported to increase ocular blood flow parameters by causing ocular vasodilation through metabolic acidosis via elevated carbon dioxide levels in the eye tissues in normal tension glaucoma patients (Sugrue 2000). A high concentration of topically applied dorzolamide has been shown to reach the choroid of the posterior pole of the eye (Sugrue et al 1990). It has been a popular adjunctive agent and is often used as monotherapy. Dorzolamide is also a safer alternative to the oral carbonic anhydrase inhibitor, acetazolamide and methazolamide, in the treatment of primary open-angle glaucoma or ocular hypertension. Dorzolamide reduces IOP from baseline at trough by $15 \%-19 \%$ and at peak by $20 \%-24 \%$.

Timolol is a non-selective beta-adrenergic antagonist. Reducing aqueous humor flow is the main mechanism by which beta blockers like timolol have been shown to lower IOP. Timolol presumably exerts a direct action on the beta- 2 adrenergic receptors in the ciliary processes to decrease aqueous humor secretion and possibly on local capillary perfusion to reduce ultrafiltration (Hoyng and Van Beek 2000; Neufeld et al 1983). Reduction of aqueous humor production may be 
secondary to inhibition of catecholamine-stimulated synthesis of cyclic adenosine monophosphate (AMP) in ciliary epithelium, which has been demonstrated in rabbit studies (Bartels et al 1980; Nathanson 1980). However, the regulation of aqueous humor dynamics is complex and still not fully understood. Studies have shown a topical timolol effect on aqueous flow in the fellow, untreated eye in patients with open-angle glaucoma and with ocular hypertension (Piltz et al 2000). Timolol decreases IOP by approximately 20\%-30\%.

Fuchsjager-Mayrl et al published a study comparing the effect of ocular flow by dorzolamide and timolol in 140 patients with POAG or ocular hypertension. At the end of the 6 months, the authors found comparable effects of both drugs on IOP and ocular perfusion pressure but statistically significant increased blood flow in the optic nerve head and choroid with dorzolamide but not with timolol (FuchsjagerMayrl et al 2005). In a study comparing Cosopt ${ }^{\circledR}$ with timolol, Cosopt $t^{\circledR}$ was found to increase the arteriovenous passage time through the superior retinal vasculature seen on fluorescein angiography (Harris et al 2001).

\section{Safety and efficacy studies}

The safety and efficacy of the fixed combination dorzolamidetimolol (FCDT) have been evaluated in several large phase III randomized controlled studies in patients with open angle glaucoma or ocular hypertension. The safety profile of the combination was essentially equivalent to concomitant administration of its components. The results also showed that the FCDT is as effective as its components used concomitantly in controlling IOP and demonstrated greater IOP lowering effect than either of its components used as monotherapy. Several independent studies have confirmed the safety and efficacy findings. The following are a summary highlighting some of the studies comparing the safety and efficacy of FCDT alone, FCDT with its components, and FCDT with other IOP-lowering topical medications.

\section{FCDT as monotherapy}

Henderer et al studied the IOP-lowering effect of FCDT as initial treatment in 18 patients with IOP over $30 \mathrm{mmHg}$ in a 2-month prospective interventional case series. Over $80 \%$ of the eyes responded to FCDT, with an average trough IOP reduction of $40 \%$. Mean peak IOP reduced from $37.5 \mathrm{mmHg}$ to $18.4 \mathrm{mmHg}(\mathrm{p}<0.01)$ (Henderer et al 2005).

\section{FCDT vs monotherapy with dorzolamide or timolol (Table I)}

The Dorzolamide-Timolol Study Group compared the safety and efficacy of FCDT to monotherapy with either timolol $0.5 \%$ twice daily or dorzolamide $2 \%$ three times daily in 335 patients after a washout of their hypotensive monotherapy agents. They found from the Phase 3 trials that FCDT provided superior IOP-lowering efficacy compared to either dorzolamide or timolol alone. The incidence of clinical adverse events was comparable in all three groups: 57 in FCDT group, 63 in dorzolamide group, and 53 in timolol group. More patients in the FCDT group than the timolol group reported ocular burning, stinging, tearing, taste perversion and blurry vision; the numbers were comparable between the FCDT and dorzolamide groups (Boyle et al 1998).

In 253 patients whose IOP was inadequately controlled on timolol montherapy, the Dorzolamide-Timolol Combination

Table I FCDT vs dorzolamide or timolol

\begin{tabular}{|c|c|c|c|c|c|c|c|}
\hline Authors & Time point & Treatment & $\mathbf{N}$ & $\begin{array}{l}\text { Baseline } \\
\text { IOP }^{a}\end{array}$ & $\begin{array}{l}\text { Treatment } \\
\text { IOPa }\end{array}$ & Change $^{a}$ & $\%$ Change \\
\hline \multirow[t]{6}{*}{ Boyle et al } & Mos 3 Trough & FCDT & 114 & $27.8(5.0)$ & $20.1(4.5)$ & $-7.7(4.2)$ & $-27.4(13.1)$ \\
\hline & & Dorzolamide & 109 & $28.1(4.7)$ & $23.5(4.2)$ & $-4.6(4.3)$ & $-15.5(13.5)$ \\
\hline & & Timolol & 111 & $27.9(4.6)$ & $21.5(4.0)$ & $-6.4(4.1)$ & $-22.2(12.5)$ \\
\hline & Mos 3 Peak & FCDT & 112 & $27.1(4.3)$ & I8.I(3.8) & $-9.0(4.3)$ & $-32.7(12.9)$ \\
\hline & & Dorzolamide & 109 & $27.3(3.8)$ & $21.8(4.3)$ & $-5.4(3.6)$ & $-19.8(12.6)$ \\
\hline & & Timolol & 110 & $27.3(4.4)$ & $21.0(4.7)$ & $-6.3(4.7)$ & $-22.6(15.6)$ \\
\hline \multirow[t]{6}{*}{ Clineschmidt et al } & Mos 3 Trough & FCDT & 102 & $25.5(3.4)$ & $22.7(3.9)$ & $-2.8(3.4)$ & $-10.6(12.5)$ \\
\hline & & Dorzolamide & 51 & $25.5(3.8)$ & $24.2(5.1)$ & $-1.4(4.3)$ & $-4.9(16.7)$ \\
\hline & & Timolol & 98 & $25.2(3.1)$ & $23.6(4.3)$ & $-1.7(3.1)$ & $-6.7(11.9)$ \\
\hline & Mos 3 Peak & FCDT & 103 & $25.0(3.9)$ & $20.7(4.5)$ & $-4.4(3.3)$ & $-17.3(12.9)$ \\
\hline & & Dorzolamide & 51 & $24.7(3.3)$ & $22.7(3.8)$ & $-2.0(4.1)$ & $-7.4(15.8)$ \\
\hline & & Timolol & 95 & $24.3(2.6)$ & $22.8(4.6)$ & $-1.6(3.7)$ & $-6.6(15.3)$ \\
\hline
\end{tabular}

${ }^{\mathrm{a}}$ measured in $\mathrm{mmHg}$.

$\mathrm{SD}$ values provided in parentheses.

Abbreviations: FCDT, fixed combination dorzolamide-timolol; IOP, intraocular pressure; mos, months. 
Study Group also found that the FCDT was superior to either of the components given individually in lowering the IOP and is as well-tolerated as the dorzolamide component. At the end of the 3 month study, the FCDT group achieved greater percentage of IOP reduction at both morning trough and peak. The safety profile of the FCDT reflected that of its individual components. The percentage of patients reporting ocular or local adverse events was equal in the FCDT (45\%) and dorzolamide (45\%) groups and greater than the timolol (27\%) group (Clineschmidt et al 1998).

\section{FCDT vs concomitant dorzolamide and timolol (Table 2)}

Francis et al (2004), Hutzelmann et al (1998), and Strohmaier et al (1998) conducted randomized trials comparing the IOP lowering effect of concomitant use of timolol $0.5 \%$ and dorzolamide $2 \%$ to that of the FCDT. The results of their studies indicate that the fixed combination was as at least as effective as its components given concomitantly in controlling IOP (no statistically significant difference). However, in the replacement study designed to mimic the "real world" uncontrolled clinical practice setting, there was a highly significant ( $p<0.0001$ ) IOP effect when switching from the concomitant use of the individual components to the FCDT, as $81.1 \%$ patients had an IOP equal to or less than the starting IOP. FCDT decreased IOP by a mean of $1.7 \mathrm{mmHg}(8.8 \%)$ from baseline of $19.4 \mathrm{mmHg}$ (Francis et al 2004). When comparing the incidence of drug-related adverse experiences and resultant discontinuations, Hutzelmann et al did not find a statistically significant difference between the FCDT group and the concomitant group (Hutzelmann et al 1998). Both the FCDT and concomitant groups lowered IOP from timolol baseline by the same percentage at trough and peak in 290 patients who completed the study (Hutzelmann et al 1998). At the end of the 3-month, multicenter, parallel, randomized, double-masked trial of 242 patients, Strohmaier et al found that FCDT lowered IOP $14 \%-20 \%$ compared to $16 \%-20 \%$ in the concomitant group, with greater than $97 \%$ confidence that the treatments were equivalent (Strohmaier et al 1998).

\section{FCDT vs concomitant brimonidine and timolol (Table 3)}

Sall et al compared the efficacy and tolerability of the FCDT twice daily to the concomitant administration of $0.2 \%$ brimonidine twice daily and $0.5 \%$ timolol twice daily. In this 6-month, randomized, multicenter, observer-masked, parallel-group study, 293 patients with ocular hypertension or primary open-angle glaucoma participated. The efficacy of the FCDT and the concomitant administration of brimonidine and timolol were comparable. Both groups had similar incidence of drug-related adverse experiences and resultant discontinuations. Ninety-three patients (64\%) in the FCDT group and 88 patients $(60 \%)$ in the concomitant group reported adverse events which the investigator attributed to the drugs; 7 patients $(5 \%)$ in the FCDT group and 8 patients $(5 \%)$ in the concomitant group discontinued the study (Sall et al 2003).

In a randomized, observer-masked, multicenter study of 492 patients with ocular hypertension, primary open-angle

Table 2 FCDT vs dorzolamide + timolol $(D+T)$

\begin{tabular}{|c|c|c|c|c|c|c|c|}
\hline Authors & Time point & Treatment & $\mathbf{N}$ & $\begin{array}{l}\text { Baseline } \\
\text { IOPa }^{-}\end{array}$ & $\begin{array}{l}\text { Treatment } \\
\text { IOP }^{\mathrm{a}}\end{array}$ & Changea & $\%$ Change \\
\hline \multirow[t]{4}{*}{ Francis et al } & Mos I & FCDT & 74 & $21.0(4.3)$ & $19.5(4.6)$ & -1.5 & -7.1 \\
\hline & Trough & $D+T$ & 57 & $19.8(3.5)$ & $19.0(3.3)$ & -0.8 & -4.0 \\
\hline & & FCDT & 74 & I8.4(3.6) & I7.6(3.6) & -0.8 & -4.3 \\
\hline & Mos I Peak & $D+T$ & 57 & 17.6(3.8) & I7.3(3.5) & -0.3 & -1.7 \\
\hline \multirow[t]{4}{*}{ Hutzelmann et al } & Mos 3 & FCDT & $|5|$ & $25.6(3.1)$ & $21.4(4.1)$ & $-4.2(3.3)$ & $-16.3(12.5)$ \\
\hline & Trough & $D+T$ & 148 & $25.3(3.2)$ & $21.1(3.7)$ & $-4.2(3.1)$ & $-16.3(11.5)$ \\
\hline & & FCDT & $|5|$ & $24.7(3.2)$ & 19.4(3.7) & $-5.4(3.1)$ & $-21.6(12.3)$ \\
\hline & Mos 3 Peak & $D+T$ & 148 & $24.5(3.2)$ & $19.1(3.5)$ & $-5.4(3.3)$ & $-21.8(11.9)$ \\
\hline \multirow[t]{6}{*}{ Strohmaier et al } & Mos 3 & FCDT & 120 & $26.1(3.0)$ & $22.5(4.1)$ & $-3.6(3.0)$ & $-13.8(11.1)$ \\
\hline & Trough & $D+T$ & 121 & $26.1(3.8)$ & $22.0(4.4)$ & $-4.1(3.7)$ & $-15.5(13.8)$ \\
\hline & & FCDT & 119 & $25.1(3.3)$ & $20.1(3.8)$ & $-5.0(3.5)$ & $-19.7(12.9)$ \\
\hline & Mos 3 Peak & $D+T$ & 120 & $25.0(3.7)$ & $20.2(4.2)$ & $-4.9(3.8)$ & $-19.1(14.4)$ \\
\hline & & FCDT & 116 & $23.7(3.9)$ & $20.0(3.9)$ & $-3.7(3.4)$ & $-14.9(13.2)$ \\
\hline & Mos $3 \mathrm{Hr} .8$ & $D+T$ & 118 & $23.3(4.2)$ & $19.0(3.5)$ & $-4.3(3.8)$ & $-17.4(14.8)$ \\
\hline
\end{tabular}

${ }^{a}$ measured in $\mathrm{mmHg}$.

SD values provided in parentheses.

Abbreviations: FCDT, fixed combination dorzolamide-timolol; IOP, intraocular pressure; mos, months. 
Table 3 FCDT vs brimonidine + timolol $(B+T)$

\begin{tabular}{|c|c|c|c|c|c|c|c|c|}
\hline Authors & Time point & Treatment & $\mathbf{N}$ & $\begin{array}{l}\text { Baseline } \\
\text { IOPa }\end{array}$ & $\begin{array}{l}\text { Treatment } \\
\text { IOPa }\end{array}$ & $\begin{array}{l}\text { Change in } \\
\text { IOPa }\end{array}$ & $\begin{array}{l}\text { Treatment } \\
\text { difference* }\end{array}$ & p-value \\
\hline \multirow[t]{8}{*}{ Solish et al } & Mos I & FCDT & 231 & $24.78(3.39)$ & $21.11(3.94)$ & $3.57(0.24)$ & & \\
\hline & Trough & $B+T$ & 238 & $24.53(3.14)$ & $20.83(4.24)$ & $-3.66(0.24)$ & $0.09(0.29)$ & 0.767 \\
\hline & & FCDT & 224 & $24.01(2.78)$ & $19.03(3.51)$ & $-4.93(0.24)$ & & \\
\hline & Mos I Peak & $B+T$ & 231 & $24.07(2.68)$ & $18.59(4.08)$ & $-5.40(0.23)$ & $0.47(0.29)$ & 0.102 \\
\hline & Mos 3 & FCDT & 235 & $24.82(3.4 I)$ & $21.23(4.39)$ & $-3.3 I(0.26)$ & & \\
\hline & Trough & $B+T$ & 243 & $25.50(3.12)$ & $20.79(3.92)$ & $-3.52(0.25)$ & $0.2 \mathrm{I}(0.3 \mathrm{I})$ & 0.491 \\
\hline & & FCDT & 228 & $24.05(2.83)$ & $19.60(3.95)$ & $-4.30(0.24)$ & & \\
\hline & Mos 3 Peak & $B+T$ & 237 & $24.03(2.68)$ & $18.58(3.95)$ & $-5.27(0.23)$ & $0.97(0.29)$ & $<0.001$ \\
\hline
\end{tabular}

${ }^{a}$ measured in $\mathrm{mmHg}$.

$\mathrm{SD}$ values provided in parentheses.

Abbreviations: FCDT, fixed combination dorzolamide-timolol; IOP, intraocular pressure; mos, months.

glaucoma, exfoliative glaucoma, or pigmentary glaucoma, Solish et al reported comparable IOP-lowering effects between FCDT and concomitant brimonidine and timolol treatment at 3 of the 4 timepoints measured at month 1 and 3 of treatment following a 3-week timolol run-in period. The only statistically significant treatment difference occurred at month 3 peak measurement, when the concomitant group had a $0.97 \mathrm{mmHg}$ additional IOP-lowering advantage over the FCDT group. The incidence of drug-related adverse experiences was similar between treatment groups. Patient-reported assessments of convenience and satisfaction showed no statistically significant differences between treatment groups (Solish et al 2004).

\section{FCDT vs prostaglandin analogs (latanoprost, bimatoprost) (Tables 4 and 4-I)}

The European Latanoprost Study Group randomized 226 patients whose IOP was insufficiently controlled by timolol alone to receive either latanoprost once daily or the FCDT twice daily. Intraocular pressure was measured at 10:00 am and 5:00 pm at baseline and after 3 months of treatment. They found that IOP reduction by monotherapy with latanoprost was comparable to that achieved by the FCDT, with a mean reduction of $19 \%$ for the latanoprost treatment group and $17 \%$ for the FCDT group $(\mathrm{p}>0.05)$ (Honrubia 2002). Likewise, Orzalesi et al found that both FCDT and latanoprost resulted in similar circadian reductions in IOP without statistically significant differences between the mean diurnal IOP values between the two groups (Orzalesi et al 2003). Fechtner et al compared the efficacy of FCDT with latanoprost in two 3-month, parallel group, randomized, double-masked, multicenter, clinical studies in patients with ocular hypertension or open-angle glaucoma. Study $1(n=256)$ was conducted in the United States and Study $2(n=288)$ was conducted in Europe/Israel. They found that FCDT and latanoprost were equally effective at lowering IOP. Both treatments reduced IOP by about 25\%-30\%. Both treatments were well tolerated,

Table 4 FCDT vs latanoprost

\begin{tabular}{|c|c|c|c|c|c|}
\hline Authors & Time point & Treatment & $\begin{array}{l}\text { Mean baseline } \\
\text { IOP }^{\mathrm{a}}\end{array}$ & $\begin{array}{l}\text { Mean treatment } \\
\text { IOP }^{a}\end{array}$ & p-value \\
\hline \multirow[t]{2}{*}{ Orzalesi et al } & Mos I & FCDT & $22.6(2.7)$ & $16.9(1.4)$ & \\
\hline & & Latanoprost & $22.6(2.7)$ & I6.7(0.6) & $>0.05$ \\
\hline \multirow[t]{4}{*}{ Fechtner et al } & Mos 3(Study I) & FCDT & 26.1 & 18.9 & \\
\hline & & Latanoprost & 25.6 & 18.4 & $>0.05$ \\
\hline & Mos 3(Study 2) & FCDT & 25.3 & 17.4 & \\
\hline & & Latanoprost & 24.7 & 17.5 & $>0.05$ \\
\hline \multirow[t]{2}{*}{ Konstas et al (2003b) } & Week 6 & FCDT & $25.8(1.4)$ & I5.3(2.0) & \\
\hline & & Latanoprost & $25.8(1.4)$ & $15.9(2.3)$ & 0.05 \\
\hline Konstas et al & Mos 2 & FCDT & $31.2(6.5)$ & $18.1(3.0)$ & \\
\hline $\begin{array}{l}\text { (pseudoexfoliation } \\
\text { patients) (2003a) }\end{array}$ & & Latanoprost & $31.2(6.5)$ & $18.9(4.1)$ & 0.21 \\
\hline \multirow[t]{2}{*}{ Susanna et al } & Mos 2 & FCDT & $23.6(3.3)$ & I7.2(3.1) & \\
\hline & & Latanoprost & $23.5(2.8)$ & $16.6(3.0)$ & $>0.05$ \\
\hline
\end{tabular}

Abbreviations: FCDT, fixed combination dorzolamide-timolol; IOP, intraocular pressure; mos, months. 
Table 4-I FCDT vs bimatoprost

\begin{tabular}{|c|c|c|c|c|c|c|}
\hline Authors & Time point & Treatment & $\begin{array}{l}\text { Mean baseline } \\
\text { IOP }^{\mathrm{a}}\end{array}$ & $\begin{array}{l}\text { Mean treatment } \\
\text { IOP }^{a}\end{array}$ & $\begin{array}{l}\text { Treatment } \\
\text { difference* }\end{array}$ & p-value \\
\hline \multirow[t]{2}{*}{ Day et al (2005) } & Mos 2 & FCDT & $24.8(2.4)$ & $\mid 8 . I(2.8)$ & & \\
\hline & & Bimatoprost & $24.8(2.4)$ & I7.4(2.9) & 0.7 & 0.35 \\
\hline \multirow[t]{2}{*}{ Ozturk et al } & Mos 6 & FCDT & $24.1(2.1)$ & 17.6(2.9) & & \\
\hline & & Bimatoprost & $23.7(2.0)$ & I7.5(2.3) & 0.3 & 0.48 \\
\hline \multirow[t]{2}{*}{ Coleman et al } & Mos 3 (8 AM) & FCDT & $24.8(2.5)$ & 19.8 & & \\
\hline & & Bimatoprost & $25.0(2.5)$ & 18.2 & 1.8 & $<0.001$ \\
\hline
\end{tabular}

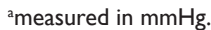

$\mathrm{SD}$ values provided in parentheses.

Abbreviations: FCDT, fixed combination dorzolamide-timolol; IOP, intraocular pressure; mos, months.

although ocular stinging occurred more frequently with the FCDT (Fechtner et al 2004).

In a randomized, open-label and cross-over study, Januleviciene et al compared the effects of FCDT and latanoprost on IOP and pulsatile ocular blood flow in 30 POAG patients. Their study found that both FCDT and latanoprost significantly reduced IOP, with FCDT exerting significantly greater IOP lowering effect than latanoprost $(\mathrm{p}<0.05)$. Both groups also significantly increased pulsatile ocular blood flow by 2.048 $\mu \mathrm{L} /$ second $(\mathrm{p}=0.003)$ and $2.147 \mu \mathrm{L} /$ second $(\mathrm{p}=0.0009)$, respectively. However, FCDT significantly increased pulse volume by $0.767 \mu \mathrm{L}(\mathrm{p}=0.0087)$, whereas latanoprost did not have a significant effect $(\mathrm{p}=0.2407)$ (Januleviciene et al 2004). Similarly, Konstas et al concluded from their study that FCDT has a small numerical $(0.6 \mathrm{mmHg})$ but statistical advantage $(p=0.05)$ over latanoprost in lowering the 24-hour diurnal IOP in patients with POAG and ocular hypertension. The FCDT lowered IOP by about $41 \%$ and and the latanoprost by about 38\% (Konstas et al 2003b).

However, in another study evaluating 65 patients with newly diagnosed exfoliation glaucoma, Konstas et al found statistically insignificant treatment difference between latanoprost and the FCDT. The FCDT showed a significantly greater incidence of taste perversion $(p<0.001)$ and stinging upon instillation $(\mathrm{p}=0.036)$, while latanoprost showed a trend for increased conjunctival injection $(p=0.056)$. In addition, five patients demonstrated either bradycardia or asthmatic symptoms with initiation of the FCDT therapy. One patient on latanoprost complained of dizziness. Patients preferred latanoprost (63 vs $20.3 \%$ ) mainly because of its once daily dosing $(\mathrm{p}<0.001)$ (Konstas et al 2003a).

Susanna et al reported results from an interventional, 8week, randomized, open-label, parallel-group study conducted at 18 centers in 6 Latin American countries. The efficacy and tolerability of latanoprost with that of the FCDT were evaluated in 229 patients with unilateral or bilateral primary open-angle, pigmentary, or exfoliative glaucoma or ocular hypertension. Mean IOP reductions were generally similar between treatment groups, except at 5:00 pm, when the mean IOP level was significantly lower in latanoprost-treated patients $(p=0.025)$. From a similar mean baseline IOP, the latanoprost group reduced IOP by $29.3 \%$ while the FCDT group reduced $26.5 \%$. After the water-drinking test, which estimates the peak IOP of diurnal tension curve, the increase in IOP values was similar between groups at baseline but lower in latanoprost-treated patients at week 8 (adjusted difference, $1.08 \mathrm{mmHg} ; \mathrm{p}=0.012$ ). Latanoprost was better tolerated than FCDT. Fewer patients treated with latanoprost reported ocular or systemic adverse events ( $p$ $=0.025$ and $\mathrm{p}<0.001$, respectively) (Susanna et al 2004).

In a double-masked, prospective, three-center, randomized, crossover study of 35 patients by Day et al the efficacy and safety of bimatoprost given every evening was compared to FCDT given twice daily for 2 months in open-angle glaucoma and ocular hypertensive patients. The study showed that both groups similarly reduced the intraocular pressures from baseline for each time point and for the diurnal curve ( $p>0.05$ ). In terms of ocular safety and tolerability, there was more conjunctival hyperemia with bimatoprost $(n=15)$ than with FCDT $(n=7, p=0.013)$ and more burning and stinging with FCDT $(n=12)$ than with bimatoprost $(n=0$, $p=0.0005$ ). Few systemic adverse events were recorded and there was no statistical difference between groups for any individual event ( $p>0.05$ ) (Day et al 2005).

In a Turkish study, Ozturk et al also reported statistically insignificant differences in IOP reduction between the bimatoprost $(6.2 \mathrm{mmHg})$ and FCDT $(6.5 \mathrm{mmHg})$ groups at all study visits $(\mathrm{p}>0.05)$ in 65 patients with POAG or ocular hypertension during 6 months of treatment. Both bimatoprost and FCDT were generally well tolerated. All but two cases of ocular adverse experiences were mild and transient in both groups. The incidence of reported ocular and systemic adverse events were statistically insignificant between the two groups except 
for conjunctival hyperemia $(n=18$ in the bimatoprost group vs 4 in the FCDT group, $\mathrm{p}=0.02$ ) (Ozturk et al 2007).

For patients whose IOP does not respond to latanoprost, adding or switching to FCDT has also been found to be beneficial. In a Spanish retrospective review of records from 31 patients (including 18 with pseudoexfoliative glaucoma), Martinez and Sanchez evaluated the intraocular pressure lowering effect of FCDT in patients with inadequate response to prostaglandin analogs/prostamides (less than 15\% IOP lowering from baseline). FCDT significantly reduced IOP in the patients overall, from 25.4 to $20.2 \mathrm{mmHg}$ ( $\mathrm{p}<0.0001$ ). FCDT reduced the mean IOP fluctuations over 12 hours (highest minus lowest IOP reading within the 12-hours pressure curve) from 8.6 to $4.3 \mathrm{mmHg}(\mathrm{p}<0.0001)$. The most common adverse events were ocular burning (16\%) and taste perversion $(13 \%)$. There were no serious treatment-related adverse events (Martinez and Sanchez 2007).

It is worth noting that a few studies have shown prostaglandin analogs as being more efficacious than FCDT in reducing IOP. In a study by Caca et al 39 POAG patients who had been using FCDT for at least three months were switched to latanoprost monotherapy. At the end of 3 months, the study showed a statistically significant reduction of mean IOP from 13.6 to $12.2 \mathrm{mmHg}(\mathrm{p}=0.01)$. Latanoprost elicted more hypermia ( $<<0.0001)$ while FCDT caused more burning on instillation $(\mathrm{p}<0.0001)$ (Caca et al 2006). Similarly, Coleman et al found that bimatoprost lowered IOP more consistently and significantly than FCDT in a 3-month randomized controlled trial on patients with glaucoma or ocular hypertension and uncontrolled IOPs on topical beta-blocker alone. Patients had better diurnal IOP control with bimatoprost than FCDT. Taste perversion, ocular burning, and stinging with instillation were more common with FCDT, whereas conjunctival hyperemia was more common with bimatoprost (Coleman et al 2003).

\section{FCDT vs concomitant timolol and unoprostone (Table 5)}

In another prospective multicenter, randomized, doublemasked, crossover comparison study, Day et al found similar efficacy and safety between FCDT and concomitant use of timolol maleate $0.5 \%$ and unoprostone $0.15 \%$ in 32 patients with primary open-angle glaucoma or ocular hypertension. After a 4-week run-in period on timolol 0.5\% twice daily, the patients received one treatment for 6 weeks and then crossed over to the opposite treatment. The authors found comparable IOP reduction for all the time points, for the diurnal curve, or in the extended reduction from baseline. There was no difference between treatment groups regarding ocular and systemic unsolicited or solicited adverse events. Burning, stinging, and conjunctival hyperemia were the adverse events most noted (Day et al 2003).

\section{FCDT vs fixed combination brimonidine-timolol (FCBT) (Table 6)}

In a prospective, multicenter, observer-masked, crossover study of 30 patients with POAG or ocular hypertension, Arcieri et al reported similar IOP-lowering efficacy by both FCDT and FCBT, with significant reduction of baseline IOP ( $p<0.00001$ ). Following 4 weeks of therapy, the mean diurnal IOP reduction was $7.8 \mathrm{mmHg}$ for FCBT and $7.4 \mathrm{mmHg}$ for FCDT ( $\mathrm{p}=0.430)$. Overall, 14 subjects complained about ocular adverse events (ocular stinging/burning, conjunctival hyperemia, itching, tearing, discharge, and dry eyes): 2 only for FCBT, 7 only for FCDT, and 5 for both drugs. Although there was no significant difference between the number of subjects that reported ocular adverse events with FCBT $(\mathrm{n}=7)$ and FCDT $(\mathrm{n}=12)(\mathrm{p}=0.359)$, FCDT caused more ocular stinging upon instillation $(\mathrm{n}=9)$ than FCBT $(\mathrm{n}=1)$ $(\mathrm{p}=0.027)$. No one discontinued the study due to the adverse experiences (Arcieri et al 2007).

\section{FCDT vs fixed combination pilocarpine-timolol (FCPT) (Table 7)}

Kaluzny et al compared the efficacy and safety of FCDT with FCPT, each given twice daily, in patients with POAG or ocular hypertensive patients. Their 6-week study found that both FCDT and FCPT resulted in similar efficacious IOP reduction. There were statistically more unsolicited reports of vision change and ocular pain associated with

Table 5 FCDT vs timolol + unoprostone $(T+U)$

\begin{tabular}{|c|c|c|c|c|c|}
\hline Authors & Time point & Mean baseline IOPa & IOP in FCDT & IOP in $T+U^{a}$ & p-value \\
\hline \multirow[t]{2}{*}{ Day et al (2003) } & Week 6 Trough & $24.3(3.0)$ & $20.8(4.1)$ & $20.1(4.5)$ & 0.55 \\
\hline & Diurnal curve & $23.4(3.2)$ & $19.6(3.6)$ & $19.8(4.1)$ & 0.63 \\
\hline
\end{tabular}

${ }^{\text {a }}$ measured in $\mathrm{mmHg}$.

$S D$ values provided in parentheses.

Abbreviations: FCDT, fixed combination dorzolamide-timolol; IOP, intraocular pressure; mos, months. 
Table 6 FCDT vs FCBT

\begin{tabular}{|c|c|c|c|c|c|c|}
\hline Authors & Time point & Treatment & $\begin{array}{l}\text { Mean baseline } \\
\text { IOPa }^{a}\end{array}$ & $\begin{array}{l}\text { Mean treatment } \\
\text { IOP }^{\mathrm{a}}\end{array}$ & $\begin{array}{l}\text { Treatment } \\
\text { difference }^{\mathrm{a}}\end{array}$ & p-value \\
\hline \multirow[t]{2}{*}{ Arcieri et al } & Mos I & FCDT & $22.9(1.6)$ & I5.4(2.I) & & \\
\hline & & FCBT & $22.9(1.6)$ & $15.0(2.1)$ & 0.4 & 0.43 \\
\hline
\end{tabular}

a measured in $\mathrm{mmHg}$.

$S D$ values provided in parenthes.

Abbreviations: FCDT, fixed combination dorzolamide-timolol; FCBT, fixed combination brimonidine-timolol; IOP, intraocular pressure; mos, months.

FCPT $(p=0.04)$. Six patients were discontinued early from FCPT therapy $(17 \%)$ versus two from FCDT $(6 \%)(p=0.13)$ (Kaluzny et al 2003).

\section{FCDT vs fixed combination latanoprost-timolol (FCLT) (Table 8)}

In another study published by Konstas et al the diurnal efficacy and safety were compared between the FCLT given once daily and the FCDT given twice daily in POAG or ocular hypertensive patients. In this double-masked, twocenter, crossover comparison of 33 patients, the daytime diurnal IOP was not statistically different between FCLT and FCDT. Additionally, they did not find statistical difference for individual time points. A bitter taste was found more frequently with FCDT $(\mathrm{n}=6)$ than FCLT $(\mathrm{n}=0)$ $(p=0.040)$, while FCLT demonstrated more conjunctival hyperemia $(\mathrm{n}=9)$ than FCDT $(\mathrm{n}=2)(\mathrm{p}=0.045)($ Konstas et al 2004).

In contrast, another study comparing FCLT and FCDT found a statistically significant difference in IOP-lowering efficacy. Shin et al enrolled 253 patients with POAG or ocular hypertension inadequately responsive to monotherapy in a 3-month, randomized, parallel group, observer-masked, multicenter study. The FCLT was found to be slightly more effective than FCDT in reducing mean diurnal IOP (9.4 mmHg vs $8.4 \mathrm{mmHg}, \mathrm{p}=0.005$ ). Both treatments generally were well tolerated. Transient eye pain during instillation of the medications was the only reported adverse event with significant difference between the two groups $(11.7 \%$ in FCDT vs. $4.0 \%$ in FCLT, $\mathrm{p}=0.034)$ (Shin et al 2004).

\section{FCDT vs concomitant brimonidine and latanoprost (Table 9)}

Zabriskie and Netland performed two double-masked, randomized, parallel, multicenter trials of similar design comparing the IOP-lowering efficacy of concomitant brimonidine $0.2 \%$ and latanoprost $0.005 \%$ with the FCDT in patients with glaucoma or ocular hypertension. The results showed that the combination of brimonidine and latanoprost produced greater mean IOP reductions at each visit in both trials (Zabriskie and Netland 2003).

\section{Patient-focused perspectives}

In addition to a medication's pharmacological potency, patient compliance also plays a major role in medication efficacy. Poor compliance leads to therapy failure. A well-known study by Kass et al showed the difficulties of compliance in a glaucoma population. Non-compliance was detected in $28 \%-59 \%$ of the patients instilling pilocarpine four times daily with a bottle embedded with a microchip sensor unbeknownst to the patients. However, $97 \%$ of the patients reported good compliance. The treating physicians could not predict which patients had poor or good compliance (Kass et al 1986).

Compliance is influenced also in part by regimen complexity. Most of the patients with glaucoma are over age 65 , have concurrent medical problems and may be taking multiple chronic medications. Greenburg found that the rate of compliance drops from $70 \%$ to approximately $50 \%$ when more than two medications (including ophthalmic) are used (Greenburg 1984). Other studies have also found an association between regimen complexity and decreased compliance

Table 7 FCDT vs FCPT

\begin{tabular}{llllll}
\hline Authors & Time point & $\begin{array}{l}\text { Mean baseline } \\
\text { IOP }^{\mathbf{a}}\end{array}$ & IOP in FCDT & IOP in FCPT & P-value \\
\hline Kaluzny et al & Week 6 Trough & $23.4(2.3)$ & $18.0(2.2)$ & $17.4(2.0)$ & 0.22 \\
& Diurnal curve & $22.3(3.7)$ & $18.1(2.2)$ & $16.7(1.9)$ & 0.0007 \\
\hline
\end{tabular}

${ }^{\mathrm{a}}$ measured in $\mathrm{mmHg}$.

$S D$ values provided in parentheses.

Abbreviations: FCDT, fixed combination dorzolamide-timolol; FCPT, fixed combination pilocarpine-timolol; IOP, intraocular pressure; mos, months 
Table 8 FCDT vs FCLT

\begin{tabular}{|c|c|c|c|c|c|c|}
\hline Authors & Time point & Treatment & $\begin{array}{l}\text { Mean baseline } \\
\text { IOPa }\end{array}$ & $\begin{array}{l}\text { Mean treatment } \\
\text { IOPa }^{\text {IO }}\end{array}$ & $\begin{array}{l}\text { Treatment } \\
\text { difference }^{a}\end{array}$ & p-value \\
\hline \multirow[t]{2}{*}{ Konstas et al (2004) } & Mos 2 & FCDT & $20.2(1.9)$ & $17.0(2.0)$ & & \\
\hline & & FCLT & $20.1(2.0)$ & $17.3(2.2)$ & 0.27 & 0.36 \\
\hline \multirow[t]{2}{*}{ Shin et al } & Mos 3 & FCDT & $27.5(3.1)$ & $19.1(3.3)$ & & \\
\hline & & FCLT & $27.9(3.6)$ & | $8.5(2.9)$ & 1.0 & 0.005 \\
\hline
\end{tabular}

${ }^{\mathrm{a}}$ measured in $\mathrm{mmHg}$.

$\mathrm{SD}$ values provided in parentheses.

Abbreviations: FCDT, fixed combination dorzolamide-timolol; FCLT, fixed combination latanoprost-timolol; IOP, intraocular pressure; mos, months.

(Patel and Spaeth 1995; Weinreb 1992). Compliance with medical therapy drops greatly when using a medication three times a day versus twice a day (Morgan et al 1986). Therefore, simplifying the treatment regimen may enhance compliance. This involves critically evaluating whether multiple medications are necessary, especially when adding medications. Combination medications such as fixed combination dorzolamide - timolol have considerable clinical value for the glaucoma patient population by simplifying treatment regimen. The improved convenience of instilling fewer daily drops with one bottle of the combination formulation and the elimination of potential confusion of frequency between two bottles of solution may enhance patient compliance. In a Swiss survey by Gugleta, increased compliance and subjective convenience were suggested reasons for the average IOP decrease of $1.5 \mathrm{mmHg}$ upon switch from dorzolamide and timolol to the combination therapy and high continuation rate on the combination therapy (Gugleta et al 2003). However, of the fixed-combination glaucoma medications, Cosopt $t^{\mathbb{R}}$ and Combigan ${ }^{\circledR}$ are used twice daily, while Xalacom ${ }^{\circledR}$ only requires a once daily regimen that may thereby increase compliance. Of these three medications Cosopt ${ }^{\circledR}$ provides the largest drop volume, and therefore the smallest number of drops per $\mathrm{mL}$. In Canada, this may partially account for the slightly higher cost of Cosopt ${ }^{\mathbb{B}}$ compared to the other two medications, with $\operatorname{Cosopt}^{\circledR}$ costing $\$ 1.22$ per day compared to $\$ 1.09$ and $\$ 0.87$ for Xalacom ${ }^{\circledR}$ and Combigan ${ }^{\circledR}$, respectively. This creates an annual cost difference between Cosopt ${ }^{\mathbb{B}}$ and Combigan ${ }^{\circledR}$ of approximately $\$ 130$. The greater cost of Cosopt $t^{\circledR}$ compared to the other fixed-combinations may hamper the patients' ability to afford the medication, so this is a real concern that must be investigated by the physician when deciding a treatment modality. The efficacy of these medications should be compared to determine if the greater cost of Cosopt ${ }^{\circledR}$ is offset by a greater efficacy in glaucoma treatment (Ventura et al 2005).

In addition to convenience and cost, tolerability is also a major component in patient compliance. Additional concerns may exist with the potential side effects of the individual components of this medication. Timolol maleate, as a betablocking agent, may have significant cardiopulmonary effects in patients as beta- 1 and beta- 2 receptors are found in the heart and lung, respectively. Those patients with known cardiac or previous chronic obstructive pulmonary disease (COPD) diagnoses should be cautioned against using this class of drug altogether. Dorzolamide is of the class sulfonamide which could lead to an allegic reaction in patients with known allergies to this class of medication. Thus, caution should be employed with all patients when subscribing this fixed combination of medicines (Ormrod and McClellan 2000). Although the fixed combination dorzolamide - timolol is generally well tolerated, it is associated with ocular discomfort on installation and led to discontinuation by a minority of patients in a number of studies. Approximately 5\% of the 1035 patients in Phase III clinical trials discontinued therapy with fixed combination dorzolamide - timolol due

Table 9 FCDT vs brimonidine + latanoprost $(B+L)$

\begin{tabular}{llllrr}
\hline Authors & Time point & Treatment & $\begin{array}{l}\text { Peak IOP } \\
\text { reduction }^{\text {a }}\end{array}$ & \% Change & p-value \\
\hline Zabriskie and Netland & Mos 3(Study I) & FCDT & 6.5 & 25.3 & 33.9 \\
& & B + L & 9.0 & 26.3 & 0.044 \\
& Mos 3(Study 2) & FCDT & 6.6 & 33.4 & 0.047 \\
\hline
\end{tabular}

${ }^{a}$ measured in $\mathrm{mmHg}$.

$S D$ values provided in parentheses.

Abbreviations: FCDT, fixed combination dorzolamide-timolol; IOP, intraocular pressure; mos, months. 
to adverse reactions. Reported in up to $30 \%$ of the patients, the most common adverse events were taste perversion or ocular burning and/or stinging. This was followed by report of conjunctival hyperemia, blurred vision, superficial punctate keratitis or eye itching by $5 \%-15 \%$ of the patients. Dorzolamide is the likely culprit since studies have reported ocular discomfort associated with dorzolamide (Barnebey and Kwok 2000; Silver 2000).

Ophthalmic medications also can pose additional problems in terms of the accuracy of drops getting into the eye, washout of drops and lacrimal drainage. The cul-de-sac of the human eye normally contains 7 to $9 \mu \mathrm{L}$ of tears and has a maximum capacity of about $30 \mu \mathrm{L}$ (Mishima 1981). The drop size of commercial glaucoma medications ranges from 25.1 to $56.4 \mu \mathrm{L}$ with an average of $39 \mu \mathrm{L}$ (Lederer and Harold 1986). Therefore, up to one-half of the medication may spill out from the lids at the time of instillation. Especially when two solutions are administered simultaneously or too closely to each other consecutively, the excess solution drains out of the lacrimal system or runs down the cheek. This medication washout is decreased by combination formulations, such as FCDT, which allows the patient to instill only one drop for both medications. Combination therapy also cuts in half the toxicity from vehicle in medication delivery and preservatives such as benzalkonium chloride (Novack and Evans 2001).

\section{Conclusions}

Efficacy and safety studies published to date show that the fixed combination dorzolamide - timolol is more efficacious than its components used individually, and at least as effective as its components used concomitantly in controlled conditions. In uncontrolled clinical settings, the combination formulation may have an additional IOP-lowering benefit, most likely due to compliance or decreased washout effect. Most studies also show fixed combination dorzolamide - timolol has efficacy comparable to other topical agents and combination agents in lowering the IOP. The role compliance plays in medication efficacy cannot be understated. As a result of increased compliance from ease of use, combination medication may provide additional benefit to the patients. Fixed combination dorzolamide - timolol is also generally well tolerated. This suggests that fixed combination dorzolamide timolol may have a beneficial role as a replacement or adjunct therapy in a clinical glaucoma practice setting when the IOP is not adequately controlled with either agent. However, one needs to keep in mind study conclusions are based on overall population results. Patients respond to the same treatment regimen in different ways. Therefore, treatment plans should always be individualized and tailored to the patient's needs as they change over time.

\section{Disclosures}

The authors have no proprietary or commercial interest in any materials discussed in the manuscript.

\section{References}

Arcieri ES, Arcieri RS, Pereira AC, et al. 2007. Comparing the fixed combination brimonidine-timolol versus fixed combination dorzolamidetimolol in patients with elevated intraocular pressure. Curr Med Res Opin, 23:683-89.

Barnebey H, Kwok SY. 2000. Patients' acceptance of a switch from dorzolamide to brinzolamide for the treatment of glaucoma in a clinical practice setting. Clin Ther, 22:1204-12.

Bartels SP, Roth HO, Jumblatt MM, Neufeld AH. 1980. Pharmacological effects of topical timolol in the rabbit eye. Invest Ophthalmol Vis Sci, 19:1189-97.

Bateman DN, Clark R, Azuara-Blanco A, et al. 2002. The effects of new topical treatments on management of glaucoma in Scotland: an examination of ophthalmological health care. Br J Ophthalmol, 86:551-4.

Boyle J, Ghosh K, Gieser D, et al. 1998. A randomized trial comparing the dorzolamide-timolol combination given twice daily to monotherapy with timolol and dorzolamide. Ophthalmology, 105:1945-51.

Caca I, Simsek H, Unlu K, et al. 2006. A comparison of latanoprost monotherapy with a combination therapy of timolol/dorzolamide in patients with primary open-angle glaucoma. Ann Ophthalmol (Skokie), $38: 111-5$.

Clineschmidt CM, Williams RD, Snyder E, et al. 1998. A randomized trial in patients inadequately controlled on timolol alone comparing the dorzolamide-timolol combination to monotherapy with timolol or dorzolamide. Ophthalmology, 105:1952-59.

Coleman A, Lerner F, Bernstein P. 2003. A 3-month randomized controlled trial of bimatoprost (LUMIGAN) versus combined timolol and dorzolamide (Cosopt) in patients with glaucoma or ocular hypertension. Ophthalmology, 110:2362-8.

Cosopt ${ }^{\mathbb{}}$ Ophthalmic Solution Prescribing Information obtained from Merck and Co., Inc. [online]. Accessed 15 September 2007. URL: http://www. merck.com/product/usa/pi_circulars/c/cosopt/cosopt_pi.pdf.

Day DG, Schacknow CJ, Wand M, et al. 2003. Timolol 0.5\%/dorzolamide $2 \%$ fixed combination vs timolol maleate $0.5 \%$ and unoprostone $0.15 \%$ given twice daily to patients with primary open-angle glaucoma or ocular hypertension. Am J Ophthalmol, 135:138-43.

Day DG, Sharpe ED, Beischel CJ, et al. 2005. Safety and efficacy of bimatoprost $0.03 \%$ versus timolol maleate $0.5 \%$ /dorzolamide $2 \%$ fixed combination. Eur J Ophthalmol, 15:336-42.

Fechtner R, Airaksinen P, Getson A. 2004. Efficacy and tolerability of the dorzolamide $2 \%$ /timolol $0.5 \%$ combination (COSOPT) versus latanoprost $0.005 \%$ (XALATAN) in the treatment of ocular hypertension or glaucoma: results from two randomized clinical trials. Acta Ophthalmol, 82:42-8.

Francis BA, Du LT, Berke S, et al. 2004. Comparing the fixed combination dorzolamide-timolol (Cosopt) to concomitant administration of $2 \%$ dorzolamide (Trusopt) and $0.5 \%$ timolol - a randomized controlled trial and replacement study. J Clin Pharm Ther, 29:375-80.

Fuchsjager-Mayrl G, Wally B, Rainer G. 2005. Effect of dorzolamide and timolol on ocular blood flow in patients with primary open angle glaucoma and ocular hypertension. Br J Ophthalmol, 89:1293-7.

Gordon MO, Beiser JA, Brandt JD, et al. 2002. The ocular hypertension treatment study: baseline factors that predict the onset of primary openangle glaucoma. Arch Ophthalmol, 120:714-20.

Greenburg RN, 1984. Overview of patient compliance with medication dosing: a literature review. Clin Ther, 6:591-9. 
Gugleta K, Orgul S, Flammer J. 2003. Experience with Cosopt, the fixed combination of timolol and dorzolamide, after switch from free combination of timolol and dorzolamide, in Swiss ophthalmologists' offices. Curr Med Res Opin, 19:330-5.

Harris A, Jonescu-Cuypers CP, Kagemann L, et al. 2001. Effect of dorzolamide timolol combination versus timolol $0.5 \%$ on ocular bloodflow in patients with open-angle glaucoma. Am J Ophthalmol, 132:490-5.

Henderer JD, Wilson RP, Moster MR, et al. 2005. Timolol/dorzolamide combination therapy as initial treatment for intraocular pressure over $30 \mathrm{mmHg}$. J Glaucoma, 14:267-70.

Honrubia FM, Larsson L, Spiegel D, et al. 2002. A comparison of the effects of intraocular pressure of latanoprost $0.005 \%$ and the fixed combination of dorzolamide $2 \%$ and timolol $0.5 \%$ in patients with open-angle glaucoma. Acta Ophthalmol Scand, 80:635-41.

Hoyng PFJ, Van Beek LM. 2000. Pharmacological therapy for glaucoma: a review. Drugs, 59:411-34.

Hutzelmann J, Owens S, Shedden A, et al. 1998. Comparison of the safety and efficacy of the fixed combination of dorzolamide/timolol and the concomitant administration of dorzolamide and timolol: a clinical equivalence study. Br J Ophthalmol, 82:1249-53.

Januleviciene I, Harris A, Kagemann L, et al. 2004. A comparison of the effects of dorzolamide/timolol fixed combination versus latanoprost on intraocular pressure and pulsatile ocular blood flow in primary openangle glaucoma patients. Acta Ophthalmol Scand, 82:730-7.

Kaiserman I, Kaiserman N, Nakar S, Vinker S. 2005. The effect of combination pharmacotherapy on the prescription trends of glaucoma medications. Glaucoma, 14:157-60.

Kaluzny J, Szaflik J, Czechowicz-Janicka K. 2003. Timolol 0.5\%/dorzolamide $2 \%$ fixed combination versus timolol $0.5 \%$ /pilocarpine $2 \%$ fixed combination in primary open-angle glaucoma or ocular hypertensive patients. Acta Ophthalmol Scand, 81:349-54.

Kass MA, Meltzer DW, Gordon M, et al. 1986. Compliance with topical pilocarpine treatment. Am J Ophthalmol, 101:515-23.

Konstas A, Kozobolis V, Tersis I. 2003a. The efficacy and safety of the timolol/dorzolamide fixed combination vs latanoprost in exfoliation glaucoma. Eye, 17:41-6.

Konstas AG, Kozobolis VP, Lallos N, et al. 2004. Daytime diurnal curve comparison between the fixed combinations of latanoprost $0.005 \%$ / timolol maleate $0.5 \%$ and dorzolamide $2 \% /$ timolol maleate $0.5 \%$. Eye, 18:1264-69.

Konstas AGP, Papapanos P, Tersis I, et al. 2003b. Twenty-four hour diurnal curve comparison of commercially available latanoprost $0.005 \%$ versus the timolol and dorzolamide fixed combination. Ophthalmology, 110:1357-60.

Lederer CM Jr, Harold RE. 1986. Drop size of commercial glaucoma medications. Am J Ophthalmol, 101:691-4.

Leskea MC, Heijl A, Hyman L, et al. 2004. Factors for progression and glaucoma treatment: the Early Manifest Glaucoma Trial. Curr Opin in Ophthalmol, 15:102-6.

Lichter PR, Musch DC, Gillespie BW, et al. 2001. Interim clinical outcomes in the collaborative initial glaucoma treatment study comparing initial treatment randomized to medications or surgery. Ophthalmology, 108:1943-53.

Martinez A, Sanchez M. 2007. Intraocular pressure lowering effect of dorzolamide/timolol fixed combination in patients with glaucoma who were unresponsive to prostaglandin analogs/prostamides. Curr Med Res Opin, 23:595-9.

Martinez GS, Campbell AJ, Reinken J, et al. 1982. Prevalence of ocular disease in a population study of subjects 65 years old and older. Am J Ophthalmol, 94:181-9.

Martone J, Mead A. 2001. Combination treatment may improve efficacy. Rev Ophthalmol, 8:82-4.

Mishima S. 1981. Clinical pharmacokinetics of the eye. Proctor lecture. Invest Ophthalmol Vis Sci, 21:504-41.
Morgan TO, Nowson C, Murphy J, et al. 1986. Compliance and the elderly hypertensive. Drugs, 31(Suppl 4):174-83.

Nathanson JA. 1980. Adrenergic regulation of intraocular pressure: identification of beta 2-adrenergic-stimulated adenylate cyclase in ciliary process epithelium. Proc Natl Acad Sci USA, 77:7420-4.

Neufeld AH, Bartels SP, Liu JH. 1983. Laboratory and clinical studies on themechanism of action of timolol. Surv Ophthalmol, 28(Suppl):286-92.

Novack GD, Evans R. 2001. Commercially available ocular hypotensive products: perservative concentration, stability, storage, and in-life utilization. J Glaucoma, 10:483-6.

Ormrod D, McClellan K. 2000. Topical dorzolamide 2\%/timolol 0.5\%: a review of its use in the treatment of open-angle glaucoma. Drugs aging, 17:477-96.

Orzalesi N, Rossetti L, Bottoli A. 2003. The effect of latanoprost, brimonidine, and a fixed combination of timolol and dorzolamide on circadian intraocular pressure in patients with glaucoma or ocular hypertension. Arch Ophthalmol, 121:453-7.

Ozturk F, Ermis S, Inan U. 2007. Comparison of the ocular hypotensive effects of bimatoprost and timolol-dorzolamide combination in patients with elevated intraocular pressure: a 6-month study. Acta Ophthalmol Scand, 85:80-3.

Patel SC, Spaeth GL. 1995. Compliance in patients prescribed eye drops for glaucoma. Ophthalmic Surg, 26:233-6.

Piltz J, Gross R, Shin DH, et al. 2000. Contralateral effect of topical betaadrenergic antagonists in initial one-eyed trials in the ocular hypertension treatment study. Am J Ophthalmol, 130:441-53.

Sall KN, Greff LJ, Johnson-Pratt LR. 2003. Dorzolamide/timolol combination versus concomitant administration of brimonidine and timolol: Six month comparison of efficacy and tolerability. Ophthalmology, 110:615-24

Schulzer M, the Normal Tension Glaucoma Study Group. 1992. Intraocular pressure reduction in normal tension glaucoma patients. Ophthalmology, 99:1469-70.

Shin D, Feldman R, Sheu W. 2004. Efficacy and safety of the fixed combinations latanoprost/timolol versus dorzolamide/timolol in patients with elevated intraocular pressure. Ophthalmology, 111:276-82.

Silver LH, Brinzolamide Comfort Study Group. 2000. Ocular comfort of brinzolamide $1.0 \%$ ophthalmic suspension compared with dorzolamide $2.0 \%$ ophthalmic solution. Results from two multicenter comfort studies. Surv Ophthalmol, 44(Suppl):S141-5.

Solish A, DeLucca P, Cassel D. 2004. Dorzolamide/timolol fixed combination versus concomitant administration of brimonidine and timolol in patients with elevated intraocular pressure. J Glaucoma, 13:149-57.

Strohmaier K, Snyder E, DuBiner H, et al. 1998. The efficacy and safety of the dorzolamide-timolol combination versus the combination administration of its components. Ophthalmology, 105:1936-44.

Sugrue MF. 2000. Pharmacological and ocular hypotensive properties of topical carbonic anhydrase inhibitors. Prog Retin Eye Res, 19:87-112.

Sugrue MF, Mallogra P, Schwam H, et al. 1990. A comparison of two topically effective ocular hypotensive carbonic anhydrase inhibitors in experimental animals. Curr Eye Res, 9:607-615.

Susanna R, Sheu W. 2004. Comparison of latanoprost with fixed-combination dorzolamide and timolol in adult patients with elevated intraocular pressure: an eight-week, randomized, open-label, parallel-group, multicenter study in Latin America. Clin Ther, 26:755-68.

Ventura MP, Saheb NE, Solari HO, et al. 2005. Cost considerations of the new fixed combinations for glaucoma medical therapy. J Clin Pharm Ther, 30:251-4.

Weinreb RN. 1992. Compliance with medical treatments of glaucoma. J Glaucoma, 1:134-6.

Zabriskie N, Netland P. 2003. Comparison of brimonidine/latanoprost and timolol/dorzolamide: two randomized, double-masked, parallel clinical trials. Adv Ther, 20:92-100. 
